\title{
Development of interest and role of choice during sequential knowledge acquisition
}

\author{
Article \\ Published Version \\ Creative Commons: Attribution 4.0 (CC-BY) \\ Open Access
}

Fastrich, G. and Murayama, K. (2020) Development of interest and role of choice during sequential knowledge acquisition. AERA Open, 6 (2). pp. 1-16. ISSN 2332-8584 doi: https://doi.org/10.1177/2332858420929981 Available at https://centaur.reading.ac.uk/90766/

It is advisable to refer to the publisher's version if you intend to cite from the work. See Guidance on citing.

To link to this article DOI: http://dx.doi.org/10.1177/2332858420929981

Publisher: SAGE

All outputs in CentAUR are protected by Intellectual Property Rights law, including copyright law. Copyright and IPR is retained by the creators or other copyright holders. Terms and conditions for use of this material are defined in the End User Agreement.

\section{www.reading.ac.uk/centaur}

\section{CentAUR}

Central Archive at the University of Reading

Reading's research outputs online 


\title{
Development of Interest and Role of Choice During Sequential Knowledge Acquisition
}

\author{
Greta M. Fastrich $(\mathbb{D}$ \\ University of Reading \\ University of Western Australia \\ Kou Murayama \\ University of Reading \\ Kochi University of Technology \\ University of Tübingen
}

\begin{abstract}
Interest is an important motivational element for learning in the school environment. However, little research has directly addressed how interest changes over time as knowledge accumulates. To gain a better understanding of how knowledge acquisition influences intraindividual change of interest, we developed a novel paradigm in which participants gain step-bystep information about lesser known countries. After reading each piece of information, participants rated their interest in the country. Growth-curve modelling showed that interest grows during knowledge acquisition until it eventually stalls and starts to decline. We also found that the opportunity to choose information boosted the growth in interest and delayed its decline. Further analysis revealed that people disengaged from a topic (i.e., stopped accessing information about a particular country) when their interest started to decrease.
\end{abstract}

Keywords: situational interest, self-determination, curiosity

INTEREST serves as one of the most important motivational and affective functioning in our everyday life. ${ }^{1}$ Interest can be conceptualized as a cognitive and affective willingness to engage in a specific activity in the absence of any extrinsic incentives (for discussion on different conceptualizations, see Renninger \& Hidi, 2011), and previous studies have shown that interest enhances a variety of outcomes, such as work performance (see Nye et al., 2012, for a review), life quality (Kashdan \& Steger, 2007), and physical health (Richman et al., 2005). Within the field of education psychology, a vast number of empirical studies have revealed the beneficial effects of interest on a variety of learning outcomes, such as student engagement (Patall et al., 2016; Renninger \& Bachrach, 2015), and course selection (Köller et al., 2001).

\section{Development of Interest}

In comparison with other motivational and emotional constructs, one of the remarkable features of interest is that it develops over time. A student cannot be interested in a specific topic or an object all of a sudden; there must be a trajectory of how the student became interested in it. Thus, to provide a comprehensive picture about human interest, it is essential to understand the mechanisms underlying interest development. There have been a number of theories that delineate the different components and possible development of interest (Krapp, 2002; Ryan \& Deci, 2000; Litman \& Jimerson, 2004). One of the most influential models is the four-phase model of interest development proposed by Hidi and Renninger (2006; see also Renninger \& Hidi, 2017, for an updated version of the model). This model posits two different types of interest-situational interest and individual interest. Situational interest refers to interest that arises in response to situational factors, whereas individual interest refers to interest that rests within the person and lets someone seek out repeated engagement with the topic of interest. Situational interest is specific to a task (Chen et al., 2001) and to a person (Schiefele, 2009), and it is normally characterized by an increased attention toward a topic, the will to learn more about it, and positive feelings toward it (Krapp, 2002). Importantly, repeated exposure to situational interest for a specific topic can lead to longer periods of situational interest until eventually the person might actively seek out information about that topic without needing a situational trigger and this phase of interest development is called individual interest. 
The longitudinal development of individual interest in school subjects has been well documented (e.g., Eccles et al., 1993; Frenzel et al., 2010; Hedelin \& Sjöberg, 1989), much less is known about the development of situational interest, for example, when reading a book or attending a class. In fact, while previous studies identified many important factors that trigger situational interest such as vividness (Sadoski, 2001; Schraw et al., 1995), novelty (Berlyne, 1960), and task difficulty (Tanaka \& Murayama, 2014), there has been substantially less empirical work that has examined the development of situational interest over time; indeed it has been pointed out that it is a topic that is poorly understood (Renninger \& Su, 2012; Tapola et al., 2013). One of the reasons is that researchers consider situational interest as variable and unstable, being influenced by many momentary factors such that it is difficult to draw a systematic growth trajectory.

In fact, when we reviewed the previous studies that tracked students' situational interest in a classroom over a specific time period (e.g., during a class, over a course, etc.), these studies provided inconsistent findings. Holstermann et al. (2012) showed that self-reported situational interest increased during a frog dissection lesson while Randler and Bogner (2007) found a decrease in self-reported situational interest over the course of an educational unit about ecosystems. Some other studies showed an even more nuanced picture on how situational interest develops. For example, Rotgans and Schmidt (2011) showed that, over the course of a problem-based learning session, students' self-reported situational interest rose up after they were introduced to the task they should do, but then it decreased over the actual work. On the other hand, Fulmer and Tulis (2013) found the opposite: During their reading task self-reported situational interest first dropped and then began to increase over the course of the task.

Although these findings are discouraging, interpretation of these findings in relation to the development of situational interest is difficult in three respects. First, although these studies examined the change in interest within a specific situation, students should have some prior knowledge about the topic, and therefore interest assessed in these studies could reflect both situational and individual interest. In fact, previous studies showed that prior knowledge is a strong predictor of individual interest in a specific topic (Alexander et al., 1994). Higher individual interest alters how people perceive and evaluate new information on a topic, potentially modulating the rewarding feeling of interest when they acquire the new information (Murayama et al., 2019). In addition, prior knowledge influences the perceived novelty of the new material. For example, a student who has paid close attention to the anatomy of the body would be able to identify the organs in a frog dissection with greater ease than a student who has little knowledge about general anatomy. Second, many aspects of these studies were not well controlled for and it is not easy to compare the findings without taking into account these contexts. In fact, Knogler et al. (2015) compared how situational interest for the same topic compared across a range of different interventions. High school students' situational interest was measured during different phases of a problem-solving task (e.g., briefing, inquiry, role-play). They found that the interest experienced during the different tasks was highly variable and only partially related to the individual interest measured before the interventions, indicating the complexity of capturing the development of situational interest. Finally, because these studies assessed situational interest only for a few time points, it is difficult to understand the precise developmental trajectory of situational interest. In fact, Ainley et al. (2002) emphasized the importance of repeated measurements to understand the nature of situational interest, given that situational interest can fluctuate at every moment.

\section{Knowledge Accumulation as a Critical Factor for the Development of Situational Interest}

The primary purpose of the current study is to detect and examine the development trend of situational interest. We specifically focus on one critical factor of interest development in a systematic manner: accumulation of knowledge or information gain. Despite a variety of theoretical perspectives, there seems to be a wide consensus that the accumulation of knowledge is critically related to interest development. Indeed, interest is often classified as one of the epistemic emotions in the literature, which refers to the emotions produced by knowledge-acquisition or knowledge generation activities (Morton, 2010; Pekrun \& Linnenbrink-Garcia, 2014; Pekrun \& Stephens, 2012). To the best of our knowledge, however, no studies have systematically investigated how the accumulation of knowledge influences the developmental trajectories of situational interest (except for less controlled studies like case studies, e.g., Pressick-Kilborn, 2015).

Importantly, to elucidate a potential systematic relationship between knowledge acquisition and situational interest, we adopted a design that addresses the critical issues identified above. In the current work, we presented participants with a series of facts from different categories (e.g., politics) about countries that really exist but people generally know little about (e.g., Chad, Dominica), and assessed participants' self-reported situational interest after the presentation of each category. This paradigm allows us to depict the developmental trajectory of situational interest as a function of the amount of information exposure in a systematic and fine-grained manner. For example, by using lesser known but existent countries as learning materials, we can control for participants' prior knowledge by design while keeping the experiment as realistic as possible. Thus, this procedure minimizes the confounding of previous knowledge that was 
present in the previous literature. Also, the information reading task we used has some educational relevance (i.e., this type of reading task is often required in education) but at the same time, it is simple enough to allow for experimental control, which was not sufficiently addressed in the previous literature. Finally, the task assesses participants' situational interest with a number of measurement points per participant and country, allowing us to understand the relatively precise developmental trajectories of situational interest.

Of course, there is an inevitable trade-off in this paradigm. For example, by controlling for prior knowledge, our paradigm essentially addresses the development of situational interest only in the early stages of interest development, that is, before people acquire substantial amount of knowledge and develop individual interest. In addition, our paradigm does not explicitly measure knowledge acquisition; we simply exposed the participants to information and did not assess their depth of understanding and degree of integration. Finally, by using a simple reading task, we did not address potential influence of many contextual and taskspecific factors. While we acknowledge the importance of these factors, to comprehensively understand the growth trajectory of situational interest in more complex educational settings, we deliberately chose this simplified and controlled paradigm with the aim to investigate a potential foundational mechanism underlying the development of situational interest.

There are at least three theories that provide us with an understanding of how this relationship might manifest. Information gap theory (Loewenstein, 1994) proposes that interest is triggered by information gaps, a discrepancy between what one knows and what one wants to know. According to the theory, we can expect that people would increase their interest as they acquire new information because the acquisition of new information would make people raise the desired level of knowledge even more, widening the gap between what they already know and what they desire to know. This theory, however, also predicts that sufficient knowledge acquisition would eventually fill the knowledge gap, decreasing interest in the topic due to the amount of surprise and novel knowledge gained being reduced. Similarly, Murayama et al. (2019) argued, in their reward learning framework, that knowledge acquisition boosts the rewarding value of new knowledge until people are subjectively satiated. In other words, they expected that new information has rewarding properties that increase situational interest over time (for the link between reward and interest, see also Hidi, 2016), but that it can also cause satiation if sufficient information is consumed. A similar prediction was also made by Kintsch (1980). In his description of cognitive interest when reading text materials, he argued that interest should be low at the beginning of a section due to the poor knowledge about the materials; afterward, interest should rise during the reading, as readers establish the sense of what is being read; finally, it diminishes again, as the novelty of the material decreases and the material becomes predictable. Thus, we expect that situational interest increases as the knowledge accumulates but it eventually goes down once substantial knowledge is acquired, producing an inverted-U relationship between the amount of knowledge accumulated and the magnitude of situational interest.

Previous studies have provided some indirect evidence for this prediction. For example, Litman et al. (2005) used general knowledge questions and examined the relationship between participants' "feeling of knowing" (about the answer) and their interest in the answer. This study showed that people's interest was highest when the feeling of knowing is relatively high but not at the highest level, indicating an inverted-U relationship. Additional indirect evidence stems from research with infants. Kidd et al. $(2012,2014)$ tested auditory and visual exploration behavior in infants. They found that infants tended to fixate the most on stimuli of medium complexity - when they are neither too complex to understand nor already known to the child. Although the research focused on the complexity of the visual stimuli, the pattern of the results bears resemblance to the inverted U-curve observed in Litman et al. (2005). However, the findings from Litman et al. (2005) were essentially correlational, as the amount of knowledge was not directly manipulated; additionally, the work by Kidd et al. $(2012,2014)$ focused only on the complexity of simple visual stimuli, making it difficult to generalize the findings to the tasks that require conceptual knowledge. As such, the relationship between the amount of accumulated knowledge and situational interest still remains an open question.

\section{Role of Choice in the Development of Situational Interest}

The current study also aims to explore the role of choice in the development of situational interest. Acquisition of knowledge should influence interest development, but in real life, knowledge is not always passively provided. We often need to actively seek information to satisfy our interest and deepen our knowledge. That is, we need to make a choice on the information we want to acquire. In the context of school learning, we are often required to regulate our learning by selecting learning materials out of our own choice and deciding the amount of time to work on specific learning materials (Murayama, Blake, et al., 2016).

However, our understanding of the precise relationship between choice and development of interest is still limited in two respects. First, although the literature has indicated that choice has positive effects on interest, none of the past empirical studies examined how choice influences the development (longitudinal trajectory) of situational interest. Indeed, most of the previous research has focused on the effects of choice on interest that was assessed only at one time point (see Patall et al., 2008, for a review). Critically, 
having an effect at a specific time point is conceptually and statistically independent of having an effect on developmental trajectories (Murayama et al., 2017). For example, it is possible that choice has a positive impact on the initial situational interest but exhibits little effects on the development of situational interest. If this is the case, the choice effect on interest may be considered as limited.

Second, there is also limited research on how interest influences people's choice of learning topic itself. When learners need to decide on learning materials themselves, interest can also serve as a motivating factor that determines people's choice behavior. If a student loses interest in the current learning materials, for example, this decreased interest may lead the student to switch to a new learning material. The relationship between people's interest and decision of disengagement/continuation has been discussed in the literature (Renninger \& Hidi, 2017) and has received some correlational support (Ennis et al., 1997). However, previous studies did not examine the relationship in the context of knowledge acquisition process, making it unclear how the knowledge acquisition, development of interest, and people's choice of disengagement or continuation from/on a task are dynamically related to each other.

To address these issues in the current work, half of the participants were allowed to select the information category that they wanted to know about, whereas the other half of participants were not. We examined how the provision of choice opportunity influenced the developmental trajectory of situational interest. Importantly, we gave participants the choice to switch to a new country and examined whether, and how, situational interest predicted people's disengagement or continuation of information seeking of a particular country. This design enables us to examine the dynamic relationship between information exposure, development of interest, and people's choice of disengagement or continuation behavior. We tentatively expected that choice opportunity would have a boosting effect on the development of interest, given that choice enables a person to select the material that has the highest appeal to them, thus potentially boosting the general interest in the topic. We also tentatively expect that interest would predict people's disengagement behavior as the feeling of interest should serve as a guide for what a person wants to study.

\section{Current Research}

In sum, the current research addresses the developmental trajectory of situational interest as a function of the amount of information exposure (Studies 1-3) and investigates the role of choice in interest change during the early stages of interest development (Studies 2 and 3). We did so by using a novel paradigm that we developed to examine the growth trajectory of situational interest in a systematic and controlled manner. We expected that participants' situational interest would grow as they read more information, but the growth eventually stops and interest goes down at some point producing an inverted-U relationship between the amount of information read and the magnitude of situational interest. We also expected that choice opportunity boosts the growth of situational interest, and situational interest in turn predicts whether participants disengage from learning the current topic.

\section{Study 1 \\ Method}

Participants. We recruited participants through Amazon. com's Mechanical Turk. We excluded participants who did not complete the experiment prior to the data analysis. In the end, 47 (21 females) U.S. participants with a mean age of 33.8 years $(S D=8.60)$ completed the task. Thirty-six participants were Caucasian, five Asian/Pacific Islanders, two Hispanic, one Native American, one African American, and one multiracial. Most of the participants reported to have either a bachelor's degree $(N=23)$ or some college education without a degree $(N=12)$ as their highest level of education. All participants reported to have English as their native language. Participants received $\$ 3$ for their participation. Note that we deliberately collected many data points from every participant to address the statistical power and the efficiency of statistical estimation: in total 4,140 data points were used for data analysis. As there are many unknown parameters in our model, conducting a priori power analysis is unrealistic. However, this overall number of data points seems to be sufficient to detect small to medium effects in standard growth curve models (Muthén \& Curran, 1997).

Materials. Materials consist of information about 24 lesser known countries (see Table 1 for examples). These countries were chosen to satisfy a high level of diversity in terms of geography (e.g., Andorra, Burkina Faso). For each country, information regarding 10 categories (e.g. "Early history," "Religion") was collected from different sources on the internet (e.g. Wikipedia; TheArda; Everyculture). The average word count per category is $101.52(S D=21.49)$ with the highest average word count found in "Demographics" (139) and the lowest in "Trivia" (59.25).

Procedure. The experiment was conducted online and was created using Collector (GitHub, n.d.). Before the start of the experiment, participants were told that their aim was to "gain some information about different countries," that the experiment would take about 40 minutes, and were asked to ensure that they would remain undisturbed during that time.

In the main part of the experiment, participants were presented with the information about countries. For a given country, the information about each category was displayed 
TABLE 1

Examples of Information Provided to the Participant

\begin{tabular}{|c|c|c|}
\hline Country & Geography & Childhood and education \\
\hline \multirow[t]{2}{*}{ Bahrain } & $\begin{array}{l}\text { The Kingdom of Bahrain is a small island country } \\
\text { situated near the western shores of the Persian } \\
\text { Gulf in the Middle East. It is an archipelago } \\
\text { with Bahrain Island, the largest land mass, } \\
\text { measuring } 55 \mathrm{~km}(34 \mathrm{mi}) \text { long by } 18 \mathrm{~km}(11 \mathrm{mi}) \\
\text { wide. It consists of } 22 \text { islands. }\end{array}$ & $\begin{array}{l}\text { Boys and girls are raised separately and according to different } \\
\text { standards. From an early age girls have much more } \\
\text { responsibility than their brothers, who have more freedom to } \\
\text { play and amuse themselves. Education is free. Primary school } \\
\text { lasts for } 6 \text { years, intermediate school for } 3 \text { years, and secondary } \\
\text { school for another } 3 \text { years. The literacy rate is } 85 \%: 89 \% \text { among } \\
\text { males and } 79 \% \text { among females. }\end{array}$ \\
\hline & $\begin{array}{l}\text { Bahrain has an arid climate. Bahrain has two } \\
\text { seasons: an extremely hot summer and a } \\
\text { relatively mild winter. During the summer } \\
\text { months, from April to October, afternoon } \\
\text { temperatures average } 40^{\circ} \mathrm{C}\left(104^{\circ} \mathrm{F}\right) \text { and can } \\
\text { reach } 48^{\circ} \mathrm{C}\left(118.4^{\circ} \mathrm{F}\right) \text { during June and July. }\end{array}$ & $\begin{array}{l}\text { There are two universities in the country: the University of } \\
\text { Bahrain with nine thousand students and the Arabian Gulf } \\
\text { University at Manama with seven hundred. The College of } \\
\text { Health Sciences trains nurses and hospital technicians. Many } \\
\text { families that can afford to do so, send their children abroad for } \\
\text { higher education. }\end{array}$ \\
\hline \multirow[t]{2}{*}{ Lesotho } & $\begin{array}{l}\text { Lesotho is the only independent state in the world } \\
\text { that lies entirely above } 1,000 \text { meters }(3,281 \mathrm{ft}) \\
\text { in elevation. Its lowest point of } 1,400 \text { meters } \\
(4,593 \mathrm{ft}) \text { is thus the highest in the world. Over } \\
80 \% \text { of the country lies above } 1,800 \text { meters } \\
(5,906 \mathrm{ft}) \text {. Lesotho is also the southernmost } \\
\text { landlocked country in the world and is entirely } \\
\text { surrounded by South Africa. }\end{array}$ & $\begin{array}{l}\text { "It takes a village to raise a child" is a well-known and accurate } \\
\text { description of African practices. Every village woman is eligible } \\
\text { to correct an erring child, to rescue one in difficulty, and to } \\
\text { encourage all. When a child is able to begin school (age varies } \\
\text { from } 5-10 \text { years), the mandatory school dress or shirt is passed } \\
\text { from one family to another. Many boys do not attend school for } \\
\text { years because they begin at age } 5 \text { or } 6 \text { to herd and care for the } \\
\text { livestock. Despite high levels of child labor, } 85 \% \text { of children } \\
\text { older than } 14 \text { years are literate. As such, Lesotho holds one of } \\
\text { the highest literacy rates in Africa. }\end{array}$ \\
\hline & $\begin{array}{l}\text { Because of its altitude, Lesotho remains cooler } \\
\text { throughout the year than other regions at the } \\
\text { same latitude. Most of the rain falls as summer } \\
\text { thunderstorms. }\end{array}$ & $\begin{array}{l}\text { A very small percentage of the population reaches a higher level } \\
\text { of education. Very wealthy families send their children to higher } \\
\text { education in England. }\end{array}$ \\
\hline \multirow[t]{2}{*}{ Moldova } & $\begin{array}{l}\text { The largest part of the nation lies between two } \\
\text { rivers, the Dniester and the Prut. The western } \\
\text { border of Moldova is formed by the Prut river, } \\
\text { which joins the Danube before flowing into } \\
\text { the Black Sea. The country is landlocked, even } \\
\text { though it is very close to the Black Sea. While } \\
\text { most of the country is hilly, elevations never } \\
\text { exceed } 430 \mathrm{~m}(1,411 \mathrm{ft}) \text {. }\end{array}$ & $\begin{array}{l}\text { Children generally grow up close to their grandparents, who } \\
\text { teach them songs and fairy tales. Girls are expected to help their } \\
\text { mothers from an early age and also take care of smaller siblings. } \\
\text { A good child is expected to be God-fearing and shy and does } \\
\text { not participate in adult conversations without being asked to do } \\
\text { so. Almost all the population is literate: the literacy rate of the } \\
\text { population aged } 15 \text { years and older is estimated at } 99.4 \% \text { (as of } \\
2015 \text { ). }\end{array}$ \\
\hline & $\begin{array}{l}\text { Moldova has a climate which is moderately } \\
\text { continental; its proximity to the Black Sea } \\
\text { leads to the climate being mild and sunny. The } \\
\text { summers are warm and long, with temperatures } \\
\text { averaging about } 20^{\circ} \mathrm{C}\left(68^{\circ} \mathrm{F}\right) \text {, and the winters } \\
\text { are relatively mild and dry, with January } \\
\text { temperatures averaging ? } 4^{\circ} \mathrm{C}\left(25^{\circ} \mathrm{F}\right) \text {. }\end{array}$ & \\
\hline
\end{tabular}

one after another and participants were encouraged to "read the information provided to [them] carefully". Categories were displayed in random order and participants could keep track of which categories were already displayed and which they would still be able to read via a sidebar (Figure 1). After reading each category information participants were asked to rate their liking of ("How much do you like this country?") and interest in the country ("How interesting do you find this country?") on a scale from 1 to 7 , with 1 indicating "not at all", and 7 indicating very much. We assessed liking in addition to interest to examine whether the pattern of results are driven by how much they liked the country; liking is a constituent element of interest but interest has some unique motivational and emotional components that cannot be reduced to liking (Silvia, 2005). By comparing the results with and without liking, we can obtain a better idea of which components of interest are responsible for the main findings. After reading the information of all categories (i.e., 10 


\section{East Timor}

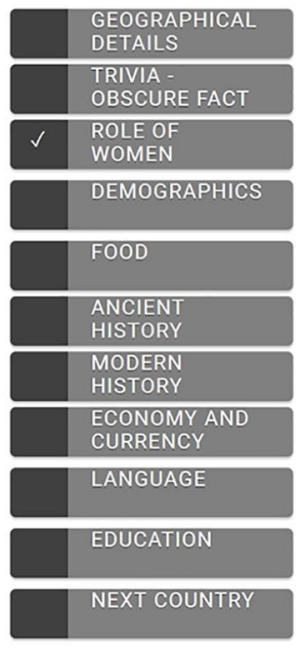

FIGURE 1. Layout of the experiment.

\section{ROLE OF WOMEN}

\begin{abstract}
Although there are some parts of East Timor that are traditionally matriarchal, patriarchy is dominant. This is reflected in numerous ways, but particularly in the practice of polygamy. Another aspect of patriarchy is that only men can own property. This is particularly an issue in the Districts, and makes the women even more financially dependent on men. This makes women vulnerable to exploitation (especially sexually)
\end{abstract}

Yet, family bonds in East Timor are very strong and especially held together by the women. Many women lost their husbands in the massacre in 1999 and many were raped during the time of oppression.

\section{Next}

categories), participants were presented with the information about another country. The presentation order of the countries was randomized across participants.

Before the first category information of a country was presented, participants answered a set of screening questions that assessed (1) whether participants had visited the country before, (2) whether they had met someone from the country before, and (3) their familiarity of the country. If participants answered the first two questions with "yes" or indicated a familiarity higher than 3 in the last question, they were immediately directed to the next country. This procedure was implemented to ensure that participants were exposed only to the countries that they did not know, allowing us to control for participants' prior knowledge about the countries. After participants passed these screening questions, they rated their initial liking and interest before seeing the first category information. If they did not know the country at all, they were asked to base their judgement on their gut feeling when they read the countries' name.

The experiment was completely self-paced. Participants went through as many countries as they could before 30 minutes after the start of the experiment had elapsed.

\section{Results}

Descriptive statistics of Study 1 can be found in the online supplement (S1).

Growth-Curve Model of Interest Development. To determine how interest developed over time as they acquire information, a three-level hierarchical growth-curve model (Level 1: trials, Level 2: countries, and Level 3: persons) was used to describe interest as a function of how much information was read about a country. The three-level growth-curve modeling allows us to examine overall growth trajectories of interest while taking into account betweencountry and between-person differences in growth trajectories. Interest was the dependent variable. The linear and the quadratic effects of information were included as predictors at Level 1. Thus, Level-1 equations are presented below:

$$
\begin{aligned}
\text { Interest }_{\mathrm{i}_{i j k}} & =\pi_{0 j k}+\pi_{1 j k} *\left(\text { Information }_{i j k}\right)+ \\
& \pi_{2 j k} *\left(\text { Information }_{i j k}\right)^{2}+\mathrm{e}_{i j k},
\end{aligned}
$$

Interest ${ }_{i j k}$ represents the interest $k$ th person in the $j$ th country at $i$ th trial. Information ${ }_{i j k}$ represents the amount of information read by the $k$ th participant for the $j$ th country at $i$ th trial. The first information was coded as 1 and the last information was coded as $10 . \pi_{0 \mathrm{jk}}, \pi_{1 \mathrm{jk}}$, and $\pi_{2 \mathrm{jk}}$ respectively represent the components of intercept, linear slope, and quadratic slope of the $k$ th participant's growth trajectories in the $j$ th country.

In the country level, we controlled for participant's initial familiarity of the country (Country Familiarity) by modeling $\pi_{0 j k}, \pi_{1 j k}$, and $\pi_{2 j k}$ as a function of Country Familiarity and residuals $r$. Hence, Level-2 equations were the following:

$$
\begin{aligned}
& \pi_{0 j k}=\beta_{00 k}+\beta_{01 k} *\left(\text { Country Familiarity }_{j k}\right)+\mathrm{r}_{0 j k}, \\
& \pi_{1 j k}=\beta_{10 k}+\beta_{11 k} *\left(\text { Country Familiarity }_{j k}\right)+\mathrm{r}_{1 j k}, \\
& \pi_{2 j k}=\beta_{20 k}+\beta_{21 k} *\left(\text { Country Familiarity }_{j k}\right)+\mathrm{r}_{2 j k},
\end{aligned}
$$

Country Familiarity was group-mean centered. Here, for example, $\beta_{00 k}$ represents the intercept of interest for person $k$ 
TABLE 2

Interest as a Function of Linear Effect of Information and Quadratic Effect of Information in Study 1 Without (Model 1) and With Liking (Model 2) as a Control Variable

\begin{tabular}{|c|c|c|}
\hline Variable & Model 1 & Model 2 \\
\hline Fixed effect & \multicolumn{2}{|c|}{ Coefficient } \\
\hline \multicolumn{3}{|l|}{ Level 1: Between trials } \\
\hline Intercept $\left(\gamma_{000}\right)$ & $3.680 * * *$ & $3.716^{* * *}$ \\
\hline Linear information $\left(\gamma_{100}\right)$ & $0.105 * *$ & $0.084 * * *$ \\
\hline $\begin{array}{l}\text { Quadratic information }\left(\gamma_{200}\right) \\
\text { Liking }\left(\gamma_{300}\right)\end{array}$ & $-0.007 * *$ & $\begin{array}{r}-0.005^{* *} \\
0.540^{* * *}\end{array}$ \\
\hline \multicolumn{3}{|l|}{ Level 2: Between countries } \\
\hline \multicolumn{3}{|l|}{ Effect of country familiarity on } \\
\hline Intercept $\left(\gamma_{010}\right)$ & $0.242 *$ & $0.240 *$ \\
\hline Linear information $\left(\gamma_{110}\right)$ & 0.004 & 0.013 \\
\hline Quadratic information $\left(\gamma_{210}\right)$ & -0.000 & -0.002 \\
\hline Liking $\left(\gamma_{310}\right)$ & & -0.035 \\
\hline Random effects & \multicolumn{2}{|c|}{ Variance } \\
\hline
\end{tabular}

\begin{tabular}{lll}
\hline Level 2: Between countries & & \\
Intercept $\left(r_{0}\right)$ & $1.113^{* * *}$ & $1.115^{* * *}$ \\
Linear information $\left(r_{1}\right)$ & $0.374 * * *$ & $0.306^{* * *}$ \\
Quadratic information $\left(r_{2}\right)$ & $0.028^{* * *}$ & $0.025^{* * *}$ \\
Level 3 - Between participants & & \\
Intercept $\left(u_{00}\right)$ & $1.271 * * *$ & $1.233^{* * *}$ \\
Linear information $\left(u_{10}\right)$ & $0.179 * * *$ & $0.120 * * *$ \\
Quadratic information $\left(u_{20}\right)$ & $0.010^{* *}$ & 0.007 \\
\hline
\end{tabular}

${ }^{*} p<.05 .{ }^{* *} p<.01 .{ }^{* * *} p<.001$.

when country familiarity is at the mean level. Similarly, $\beta_{11 k}$ represents the influences of Country Familiarity (of the $k$ th participant in the $i$ th country) on the relationship between linear information (Information) and interest for participant $k$. In the person level, only residuals $(u)$ were included. For example, for $\beta_{00 k}$ and $\beta_{01 k}$, the Level-3 equation looks like the following:

$$
\begin{aligned}
& \beta_{00 k}=\gamma_{000}+u_{00 k}, \\
& \beta_{01 k}=\gamma_{010}+u_{01 k},
\end{aligned}
$$

where $\gamma_{000}$ and $\gamma_{010}$ represents the intercepts and $u_{00 \mathrm{k}}$ and $u_{01 \mathrm{k}}$ represent the deviation from the intercept for a specific participant (i.e., residual).

The analyses were conducted using HLM 7 (Raudenbush et al., 2011). The parameters were estimated on the basis of full maximum-likelihood estimation. Given the large number of random effects, which often leads to convergence errors or unstable parameter estimates, only random effect variances with $p<.5$ were included in the final model.

Parameter estimates are reported in Table 2. Figure 2 displays the estimated growth curves of interest. The results showed that interest increases significantly as the amount of

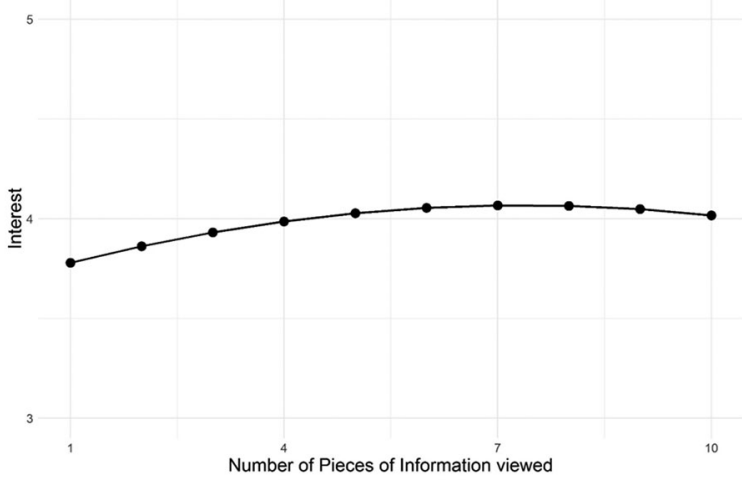

FIGURE 2. Model predictions of interest development in Study 1. Predictions were calculated by resolving the model equations for the Information Steps 1 to 10. Country familiarity was kept constant as the average of the collected data set.

information increases $\left(\gamma_{100}=0.105, p=.005\right)$. This trend, however, stops and then begins to decrease over time as can be seen by the significant negative quadratic effect of information $\left(\gamma_{200}=-0.007, p=.005\right)$. These results are consistent with our hypothesis that interest development follows an inverted- $U$ shape as a function of knowledge accumulation. Initial familiarity with the countries did not have significant impacts on the development of interest or its change $(p \mathrm{~s}>.05)$.

To disentangle the effects of liking and other elements in interest, we also included liking as a Level-1 controlling variable (with group-mean centering). We replicated these results with the current liking of the country included as a control variable. Results show a similar pattern (see Table 2).

\section{Discussion}

The results of Study 1 showed that both interest for a topic grow with the amount of information gathered. However, this trend does not continue limitlessly; instead, the growth of interest slows down (negative quadratic term) and even starts to decline at a certain point. This inverted-U relationship between the amount of information and interest is consistent with previous theoretical suggestions e.g., Kintsch, 1980; Loewenstein, 1994; Murayama et al., 2019), but to our knowledge, this is the first demonstration of this theoretical prediction with a strict manipulation of participant's information levels.

\section{Study 2}

Study 2 aimed to replicate the findings and extends them by examining the role of choice in the development of interest. In Study 1, participants were presented with a series of 
information which was randomly selected by the program. In Study 2, in contrast, participants were given the choice how many pieces of category information they wanted to read. Half of them were also able to select the categories. We aimed to examine how choice manipulation would influence the development of interest observed in Study 1 and examine the effects of choice on continuation/disengagement of information seeking behavior.

\section{Method}

Participants. Again, only participants who completed the experiment were included. Seventy-five (39 female; $M$ age $=36.3$ years; $S D=11.56$ ) participants were recruited over Amazon's MTurk. Participants either participated in the full-choice $(N=38)$ or partial-choice condition $(N=37)$. Fifty-two participants were Caucasian, nine African American, seven Asian/Pacific Islanders, five Hispanic, and two did not report their ethnicity. Most reported to have either a bachelor's degree $(N=23)$, some college education without a degree $(N=19)$, or a high school degree $(N=17)$ as their highest level of education. All participants reported to have learned English during their early childhood. Again, participants received $\$ 3$ for their participation. A total of 3,305 data points was collected.

Materials and Procedure. The materials and basic procedure were the same as in Study 1. However, unlike Study 1, all participants were only required to read the information on 0 to 4 information categories (randomly sampled) for each country and to rate liking and interest each time after reading the information. We decided to include these "familiarization" trials to prevent participants from mindlessly moving to the next country and to catch and randomly vary participants' initial interest. Critically, in the end of the last familiarization trials, participants were given the choice of whether they wanted to gain more information about the same country (i.e., continue) or discontinue the current country and move on to a different country (i.e., disengagement). If they decided to continue, they saw another piece of information on the same country, rated liking and interest about the country, and made the same decision again. This process was repeated until the participant decided to discontinue and move on to the next country. When participants decided to discontinue the current country, a new country name was presented and (after the screening questions) familiarization trials started again. Participants were not aware of which country they would see next if they decided to disengage from the current country. In the full-choice condition, participants could choose the category from which they want to gain information after the familiarization trials (e.g., Demographics). In the partial-choice condition, participants could choose to see more information after the familiarization trials, but the category was randomly selected (by the program) like Study 1.

\section{Results}

General descriptive statistics of Study 2 can be found in the online supplement (S2).

Growth-Curve Model of Interest Development. All of the following analyses were run in HLM 7. We first tried to replicate the model from Study 1 with the data set of Study 2. However, we included additional predictors. At the trial level the variable Familiarization was added that represents whether participants were in the familiarization trials $($ Familiarization $=1)$ or not $($ Familiarization $=-1)$. Hence, the Level-1 equation for the $i$ th trial in the $j$ th country for the $k$ th participant was

$$
\begin{aligned}
\text { Interest }_{i j k} & =\pi_{0 j k}+\pi_{1 j k} *\left(\text { Information }_{i j k}\right)+ \\
& \pi_{2 j k} *\left(\text { Information }_{i j k}\right)^{2}+ \\
& \pi_{3 j k} *\left(\text { Familiarization }_{i j k}\right)+\mathrm{e}_{i j k},
\end{aligned}
$$

where the outcome variable, Interest ${ }_{i k i}$ represents the amount of interest that participant $k$ reported after they read the $i$ th information about a country $j$.

The between-country variability of the intercept and regression slopes $\pi_{0 j k}$ to $\pi_{3 i k}$ were estimated at Level 2 (countries). We controlled for the familiarity with the country as well as the amount of information read for that specific country (i.e., the number of category information read before going to the next country). Specifically, parameters $\pi_{0 j k}$ to $\pi_{3 j k}$ were expressed as a function of familiarity with the country (Country Familiarity), the total amount of information read about the country before switching (Total Information), and residuals $r$. Here are two example equations.

$$
\begin{gathered}
\pi_{0 j k}=\beta_{00 k}+\beta_{01 k} *\left(\text { Country Familiarity }_{j k}\right)+ \\
\beta_{02 k} *\left(\text { Total Information }_{j k}\right)+\mathrm{r}_{0 j k}, \\
\pi_{1 j k}=\beta_{10 k}+\beta_{11 k} *\left(\text { Country Familiarity }_{j k}\right)+ \\
\beta_{12 \mathrm{k}} *\left(\text { Total Information }_{j k}\right)+\mathrm{r}_{l j k},
\end{gathered}
$$

Note that, to facilitate the interpretability of the coefficients (see Biesanz et al., 2004), Total Information was rescaled so that Total Information $=0$ represents the case that participants read all 10 pieces of information available for a country. That is, Total Information is coded as -1 when participants read nine pieces of category information, -2 when participants read eight pieces of category information, and so on. Country familiarity was again group-mean centered. With this coding scheme, for example, $\beta_{00 k}$ represents the average intercept value of interest for participant $k$ when country familiarity is at the mean and participants read all 10 pieces of information; $\beta_{11 k}$ represents the influences of Country Familiarity (of the $k$ th participant in the $i$ th country) on the relationship between linear information (Information) and interest for participant $k$. We preferred this coding 
scheme because this coding scheme allows us to compare the results from Study 1 and Study 2 relatively easily, because participants always read 10 categories of information for each country in Study 1.

The between-person variability of the $\beta$ parameters were estimated at Level 3 (participants). Here the choice condition (Choice: partial choice $=-1$; full choice $=1$ ) was added to the equation as well. Again, two example equations $\left(\beta_{00 k}\right.$ and $\left.\beta_{11 k}\right)$ are provided. Other $\beta$ parameters are estimated with the same pattern.

$$
\begin{aligned}
& \beta_{00 k}=\gamma_{000}+\gamma_{001} *\left(\text { Choice }_{k}\right)+u_{00 k}, \\
& \beta_{11 k}=\gamma_{110}+\gamma_{111} *\left(\text { Choice }_{k}\right)+u_{01 k},
\end{aligned}
$$

For example, $\gamma_{110}$ is the (average) effects of country familiarity on the slope between (linear) information and interest; $\gamma_{111}$ represents the extent to which the condition moderates the previous effect. Like in Study 1, only random effects with a $p$ value $<.5$ were included.

Parameter estimates are reported in Table 3. Like Study 1 , interest $\left(\gamma_{100}=0.443 ; p<.001\right)$ increased with increased amount of information. This effect is stronger for the fullchoice condition $\left(\gamma_{101}=0.208 ; p<.001\right)$, indicating that choice opportunity has positive effects on the development of interest. There is a significant effect of the total amount of presented information before switching to the next country on interest development over the course of information acquisition $\left(\gamma_{120}=0.053 ; p<.001\right)$. Again, this effect is more pronounced in the full-choice condition $\left(\gamma_{121}=0.030\right.$; $p=.005)$. Replicating Study 1 again, the growth interest as a function of the presented information became weaker over time as indicated by significant negative quadratic effects $\left(\gamma_{200}=-0.032 ; p<.001\right)$. This effect is stronger in the full-choice condition $\left(\gamma_{201}=-0.019 ; p=.001\right)$. When we included liking as a controlling variable like Study 1, we found a similar pattern of results, with the key effects remaining statistically significant (see Table 3 ).

Figure 3 draws the estimated growth curves of interest, as a function of choice condition and total number of information. Overall, the results seem to replicate the findings of Study 1 and be consistent with our hypothesis. That is, there was an inverted-U relationship between the amount of presented information and interest. In addition, Figure 3 indicates that interest has positive effects on both intercept and the linear component of the growth curve. The current results further showed that providing a full choice over the information to read boosts people's overall interest.

Choice Behavior. One important insight into Figure 3 is that, regardless of the amount of information people read before switching to the next country, there seems to be a slight dip in interest, indicating that the change in interest may be a driver for participants to decide whether they continue or disengage from the current country.
To examine how and why people decided to move to another country by terminating the information seeking of the current country, we conducted an exploratory analysis with disengagement as the dependent variable. We developed two models for comparison. The first model is a simple model which expresses the choice to disengage (Disengagement $=1$; Continue with same country: 0 ) as a function of the number of category information that the participants already saw about the country (Model 1) and interest (Level-1 predictors). The next model added the interest of the previous trial as a new predictor (Model 3). To examine if the liking of information has an impact on our results, we ran two additional models which included liking as a control variable (Model 2 and Model 4). We applied these models to the dataset where we eliminated familiarization trials. As some participants did not have eligible data for these analyses, only 61 participants were included.

The results are reported in Table 4. Interest was not a significant predictor of disengagement (Model 1: $\gamma_{200}=-0.121$; $p=.638$; Model 3: $\left.\gamma_{200}=-0.214 ; p=.394\right)$. Even when Liking is controlled for, this effect remains not significant (Model 2: $\gamma_{200}=0.088 ; p=.732$; Model 4: $\gamma_{200}=0.024 ; p$ $=.926$ ). Importantly, however, Model 3 showed that when current interest was controlled for, the previous interest positively predicted the chance that people would stop sampling information about the current country (Model 3: $\gamma_{300}=$ $0.752 ; p<.001)$. This pattern remained significant even after controlling for previous liking as an additional predictor (Model 4: $\gamma_{400}=0.825 ; p<.001$ ). These results indicate that, if interest in the current trial is held constant, higher interest in the previous trial is likely to lead to disengagement. In other words, people stop collecting information when interest in a country starts to stall or decrease. The condition has no significant effects on the way interest influences choice behavior.

\section{Discussion}

Study 1 and 2 showed a coherent picture: Interest increases over time but the growth of interest eventually stalls and even dips toward the end. This pattern was observed regardless of whether decisions about information could be made but choice opportunity boosted the increase in interest. These results are echoed in the choice behavior: The choice of whether to view more information about the current country or move on the next one seems to be driving decline in interest in the country. People stop sampling information when their judgment about their own interest starts to fall again.

\section{Replication Study}

Because Study 2 involved a relatively complicated design, we decided to conduct a simple (direct) replication study with a larger sample size (187 participants; 98 female; 
TABLE 3

Main Parameter Estimates of the Growth Curve Model From Study 2, Without Liking Controlled (Model 1) and With Liking Controlled (Model 2)

\begin{tabular}{|c|c|c|}
\hline \multirow{2}{*}{$\frac{\text { Variable }}{\text { Fixed effects }}$} & Model 1 & Model 2 \\
\hline & \multicolumn{2}{|c|}{ Coefficient } \\
\hline \multicolumn{3}{|l|}{ Level 1: Between trials } \\
\hline Intercept (average) $\left(\gamma_{000}\right)$ & $4.536 * * *$ & $4.701 * * *$ \\
\hline Linear information intercept $\left(\gamma_{100}\right)$ & $0.443 * * *$ & $0.313 * * *$ \\
\hline Quadratic information intercept $\left(\gamma_{200}\right)$ & $-0.032 * * *$ & $-0.023 * * *$ \\
\hline Liking $\left(\gamma_{400}\right)$ & & $0.466^{* * *}$ \\
\hline \multicolumn{3}{|l|}{ Level 2: Between countries } \\
\hline \multicolumn{3}{|l|}{ Effect of total information on } \\
\hline Intercept $\left(\gamma_{020}\right)$ & $0.101 * * *$ & $0.126^{* * *}$ \\
\hline Linear information $\left(\gamma_{120}\right)$ & $0.053 * * *$ & $0.034 * *$ \\
\hline Quadratic information $\left(\gamma_{220}\right)$ & -0.001 & -0.001 \\
\hline Liking $\left(\gamma_{420}\right)$ & & -0.003 \\
\hline \multicolumn{3}{|l|}{ Level 3: Between participants } \\
\hline \multicolumn{3}{|l|}{ Effect of choice condition on } \\
\hline Intercept (average) $\left(\gamma_{001}\right)$ & 0.013 & 0.112 \\
\hline Linear information $\left(\gamma_{101}\right)$ & $0.208^{*}$ & $0.142 *$ \\
\hline Quadratic information $\left(\gamma_{201}\right)$ & $-0.019^{*}$ & $-0.014^{*}$ \\
\hline Liking $\left(\gamma_{401}\right)$ & & $0.152 * *$ \\
\hline Total information $\times$ Intercept (average) $\left(\gamma_{021}\right)$ & -0.015 & -0.001 \\
\hline Total information $\times$ Linear information $\left(\gamma_{121}\right)$ & $0.030 *$ & 0.021 \\
\hline Total information $\times$ Quadratic information $\left(\gamma_{221}\right)$ & -0.003 & $-0.003 *$ \\
\hline Total information $\times$ Liking $\left(\gamma_{421}\right)$ & & 0.013 \\
\hline Random effects & & \\
\hline \multicolumn{3}{|l|}{ Level 2: Between countries } \\
\hline Intercept (average) $\left(r_{0}\right)$ & $0.957 * * *$ & $0.973 * * *$ \\
\hline Linear information intercept $\left(r_{1}\right)$ & $0.412 * * *$ & $0.310 * * *$ \\
\hline Quadratic information intercept $\left(r_{2}\right)$ & $0.037 * * *$ & $0.027 * * *$ \\
\hline \multicolumn{3}{|l|}{ Level 3: Between participants } \\
\hline Intercept (average) $\left(u_{000}\right)$ & $0.751 * * *$ & $0.749 * * *$ \\
\hline Linear information intercept $\left(u_{100}\right)$ & $0.160 * * *$ & $0.116^{* * *}$ \\
\hline Quad. information intercept $\left(u_{200}\right)$ & 0.014 & 0.010 \\
\hline \multicolumn{3}{|l|}{ Effect of total information on } \\
\hline Quadratic information $\left(u_{220}\right)$ & $0.007^{*}$ & $0.004 * *$ \\
\hline
\end{tabular}

Note. Variance is estimated at the level above (e.g., $r$ variance is estimated on the country level). The models are explained in the main texts. For the purpose of simplicity, we omitted the parameter estimates related to original country familiarity but the full parameter estimates can be found in the online Supplemental Table S1.

${ }^{*} p<.05 . * * p<.01 . * * * p<.001$.

$M$ age $=37.3$ years; $S D=10.93$ ) on MTurk, to examine the robustness of our findings. The procedure was identical. However, because we observed significant individual differences in the growth curve in Studies 1 and 2, for exploratory purpose, we also assessed several personality traits of participants (e.g., need for cognition; Cacioppo \& Petty, 1982) to examine the possibility that personality traits explain the individual differences. The study is reported in the online supplement (S3). Overall, results from the previous studies were replicated, and there is little evidence that personality traits that we assessed explain the individual differences in the growth curve. In particular, we were not able to find any significant effects of the self-developed scales measuring general knowledge and interest in countries and cultures on growth trajectories.

\section{General Discussion}

Current research examined the growth trajectory of situational interest as a function of the sequential information exposure, and the role of choice in the development of situational 


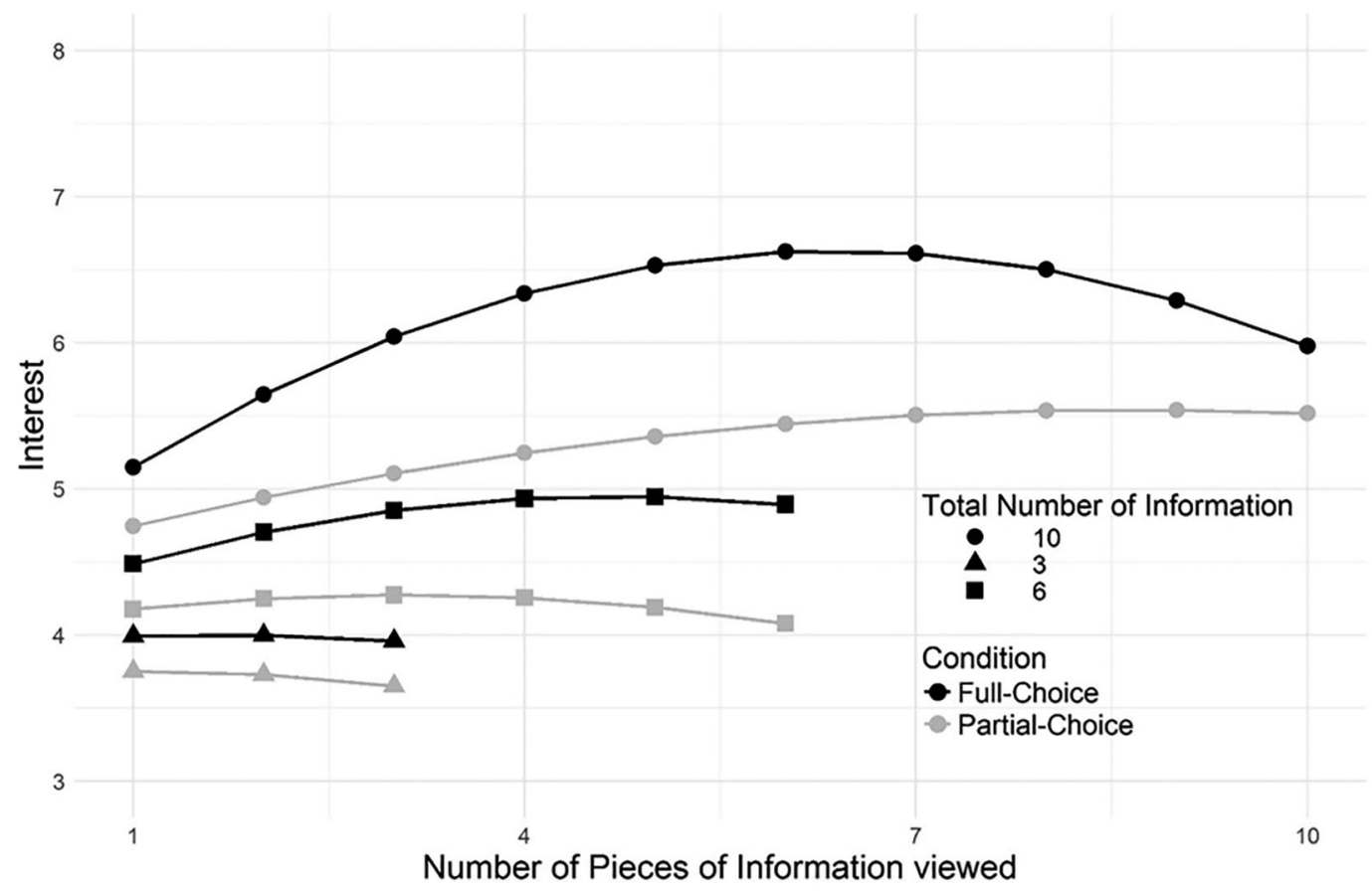

FIGURE 3. Model predictions of interest development in Study 2. Predictions were calculated by resolving the model equations for the different information Steps $(1-3 ; 1-6 ; 1-10)$. Country familiarity was kept constant as the average of the collected dataset. Three levels of Total Information were used $(3,6,10)$. Separate lines for choice and random condition were calculated.

interest in the early stages of interest development. With three studies using a new paradigm that allows us to examine the relationship between knowledge acquisition - manipulated by the amount of information people read-and situational interest in a fine-grained manner, we showed that the amount of information read and interest development have an inverted-U relationship. Specifically, our growth-curve modelling showed that situational interest grows during information gain until it eventually stalls and starts to decline. In addition, we also found that the opportunity to choose information boosts the initial growth in situational interest, and that people disengage from information search when their situational interest starts to decrease.

Situational interest is triggered by many different external factors (e.g., novelty, surprise, etc.) and has been considered as unstable and variable in its nature. By utilizing a research paradigm that allows for a number of repeated measurements of situational interest and controls for extraneous factors (e.g., prior knowledge), we showed that situational interest changes over time in our information reading task. It is interesting to note that the acquisition of knowledge seemingly runs counter to some of the critical factors identified in previous studies that trigger situational interest such as novelty and surprise (Anderson et al., 1987; Sadoski, 2001; Swarat et al., 2012), as better knowledge should lose the freshness of the learning materials and could reduce the feeling of novelty and surprise. Consistent with several theoretical perspectives (e.g., Alexander et al., 1995; Murayama et al., 2019; Renninger \& Hidi, 2017; Silvia, 2005), our results indicate that knowledge is an important driver for the systematic maintenance and development of situational interest.

\section{Change of Interest Predicts Disengagement}

One of the interesting observations from the current study is that the primary predictor for disengagement with a current country was the change of interest-if participants disengaged when the change of the interest was relatively small. This relationship provides a nuanced view on how interest influences our decision making. Many previous studies have indicated that interest triggered by the current piece of information is a predictor of different kinds of learning behavior (e.g., Schiefele et al., 1992; Schraw et al., 1995). However, Figures 2 and 3 suggest that, when disengagement occurred, participants' interest level seemed to be higher than their initial interest level, indicating that the current level of interest alone is unable to capture the whole picture of participants' disengagement behavior. One potential account of this "marginal gain effect" is that change in interest may represent a subjective surprise or novelty and it is this surprise or novelty that actually drives our behavior. When participants read information about a country that they were unfamiliar with, the first piece of information is likely to be highly surprising to them. However, with more knowledge about the country 
TABLE 4

Comparison of the Four Models of Choice Prediction From Study 2

\begin{tabular}{|c|c|c|c|c|}
\hline Variable & Model 1 & Model 2 & Model 3 & Model 4 \\
\hline Fixed effects & \multicolumn{4}{|c|}{ Coefficient } \\
\hline \multicolumn{5}{|l|}{ Level 1: Between trials } \\
\hline Intercept (average) $\left(\gamma_{000}\right)$ & $-1.779 * * *$ & $-1.796 * * *$ & $-1.616^{* * *}$ & $-1.561 * * *$ \\
\hline Linear information $\left(\gamma_{100}\right)$ & $0.297 * * *$ & $0.298 * * *$ & $0.247 * * *$ & $0.224 * * *$ \\
\hline Interest $\left(\gamma_{200}\right)$ & -0.121 & 0.088 & -0.214 & 0.024 \\
\hline Liking $\left(\gamma_{300}\right)$ & & $-0.572 * * *$ & & $-0.694 * * *$ \\
\hline Previous interest $\left(\gamma_{300 / 400}\right)$ & & & $0.752 * * *$ & $0.825^{* * *}$ \\
\hline Previous liking $\left(\gamma_{500}\right)$ & & & & 0.123 \\
\hline \multicolumn{5}{|l|}{ Level 3: Between participants } \\
\hline \multicolumn{5}{|l|}{ Effect of condition on } \\
\hline Intercept (average) $\left(\gamma_{000}\right)$ & $-0.873 * *$ & $-0.891 * *$ & $-0.855^{* *}$ & $-0.878 * *$ \\
\hline Linear information $\left(\gamma_{110}\right)$ & $0.329 * * *$ & $0.337 * * *$ & $0.320 * * *$ & $0.328 * * *$ \\
\hline Interest $\left(\gamma_{200}\right)$ & 0.359 & 0.323 & 0.406 & 0.378 \\
\hline Liking $\left(\gamma_{300}\right)$ & & 0.143 & & 0.091 \\
\hline Previous interest $\left(\gamma_{300 / 400}\right)$ & & & -0.104 & -0.114 \\
\hline Previous liking $\left(\gamma_{500}\right)$ & & & & 0.165 \\
\hline Random effects & & & & \\
\hline \multicolumn{5}{|l|}{ Level 2: Between countries } \\
\hline Intercept (average) $\left(r_{0}\right)$ & 0.580 & 0.576 & $0.573 *$ & 0.474 \\
\hline Linear Information $\left(r_{1}\right)$ & $0.186^{* *}$ & $0.185^{* *}$ & $0.178 * *$ & $0.146^{*}$ \\
\hline \multicolumn{5}{|l|}{ Level 3: Between participants } \\
\hline Intercept (average) $\left(u_{00}\right)$ & $1.619 * *$ & $1.636^{* *}$ & $1.580 * *$ & $1.607 * * *$ \\
\hline Linear information $\left(u_{10}\right)$ & $0.261^{*}$ & 0.255 & $0.259^{*}$ & $0.274 *$ \\
\hline Interest $\left(u_{20}\right)$ & $1.057 * *$ & $0.954 * *$ & $0.986^{* *}$ & $0.891^{*}$ \\
\hline Previous interest $\left(u_{40}\right)$ & & & & 0.688 \\
\hline
\end{tabular}

$* p<.05 . * * p<.01 . * * * p<.001$.

accumulated, participants should be able to have a better prediction about information that they are about to read. Such expectation is likely to decrease the surprise evoked by the new information, leading to slower (or even negative) growth in task interest and task disengagement. In other words, once participants become familiar with a country, their interest starts to decline and they stop seeking information, even though, the overall information about the country is still deemed interesting.

The psychological mechanisms that we laid out are still hypothetical and require further investigation, but it is worth noting that there is another complication to understand the development of interest and its relation to task engagement. So far, we interpreted the switch to another country as disengagement, but this switching behavior may also reflect people's natural tendency to seek variety in what they explore. Indeed, research in consumer behavior has shown that people seek variety in actions and products chosen (for a review, see Kahn \& Ratner, 2005) even to a point where they choose less-favorable options to diversify their experiences (Ratner et al., 1999; Read \& Loewenstein, 1995). Palmer (2009) argued that people prefer variety because variety acts as a form of novelty, and perhaps this variety-seeking behavior may be people's self-regulation strategy to sustain their task interest. In fact, Sansone et al. (2012) also showed that university students in an online course explored a variety of options of their online materials as a method to increase their interest. Accordingly, in the current experiment, the desire to experience variety was operative in competition with the motivation to be engaged in a specific topic, and that it is difficult to disentangle these two mechanisms. We believe that this is an inherent confound in disengagement behavior in general and not specific to our study design - it is not easy to examine disengagement behavior independently of people's interest in alternative options, because the decision to disengage always involves the comparison between the value of the current option and the value of the alternatives. However, future studies should consider a potential experimental paradigm that allows us to separate these two mechanisms underlying the disengagement behavior. 


\section{Effects of Choice on Interest Development}

Previous studies have indicated that the provision of choice opportunities is beneficial for motivation (for reviews, see Murayama, Izuma, et al., 2016; Patall et al., 2008), and the current study added to these findings by showing that choice opportunities can boost the growth (change) (although the effect was marginally significant in Study 3-see the online supplement S3). Specifically, initial interest growth is stronger in the full choice condition than the partial-choice condition. These findings indicate an important role played by personal choice to facilitate and sustain students' interest in the course of learning. We suspect that this choice opportunity would also be a key factor that supports the transition from situational interest to individual interest, making students more autonomous and independent learners who can study out of their own interest. Future research should examine the effects of choice on a longer term development of interest.

Another interesting finding is that the inverted U-shape of the growth curve is more pronounced in the full-choice condition than the partial-choice condition, suggesting a stronger drop in interest growth after it reached the peak of assessed interest in the full choice condition. At first glance, these findings may be difficult to interpret, but actually the pattern is consistent with the inherent property of voluntary choice. Specifically, if given the choice, participants are likely to select the information about the categories they prefer. Consequently, after their assessed interest level peaked, participants are likely to be left with the categories they are less interested in, resulting in rapid decline in overall task interest and potential disengagement when no interesting category is left. In fact, previous work suggested that people are drawn naturally to categories whose information they find more interesting (see Hidi \& Baird, 1986). In other words, the participant's biased selection of categories contributed to this seemingly puzzling effect of choice (i.e., item selection effect — see Murayama, Blake et al., 2016).

\section{Limitations}

A few limitations should be noted, some of which were already mentioned in the introduction. First, we did not address the potential influence of contextual and task factors that are likely to play a critical role in the development of interest in real educational settings. In fact, previous studies have shown that situational interest is a function of different factors. Among others, task characteristics (e.g., Knogler et al., 2015), person characteristics, like previous knowledge or self-concept of ability (e.g., Durik et al., 2015), and learning environment (e.g., Thoman et al., 2007) can influence its growth. We used a simplified task to purposefully control for these factors, so that we could investigate the foundational underlying mechanisms of the development of situational interest. However, we by no means claim that these contextual and task factors are unimportant. Rather, we view our findings complementary with these previous findings, and suggest that future research should examine how the relationship between knowledge acquisition and interest development is modulated by contextual and task factors. This way, we should be able to explain dynamic and complex developmental change in interest observed in real education settings. To investigate these dynamics in children, it will be important to replicate our findings with a younger population as differences in overall general knowledge or stages of individual development might influence the development of situational interest.

Second, the current work only manipulated the amount of information, and did not directly assess the depth of the knowledge participants acquired. While it is unlikely that participants retained no change to their knowledge structures in the course of the experiment, future studies should investigate whether and how interest development depends on the depth and quality of the knowledge gain and replicate the findings with more explicit measures of knowledge. In fact, in all studies, there is relatively large and statistically significant heterogeneity in the linear growth in interest $\left(u_{100}\right.$ and $u_{200}$ in Tables 2 and 3, and online Supplemental Table S1), meaning that there are participants who did not exhibit increase in situational interest as they acquire knowledge or might even exhibit a decrease in interest (although such participants were a minority in comparison with those who showed increase). The depth and the quality of knowledge gain may be (at least in part) reflected in such individual differences.

Third, we relied on a single self-reported question to assess participants' situational interest. While we controlled for the "liking" rating to ensure that our findings are more than just a mere reflection of affective reactions (e.g., general positive feelings), self-reported questions are subject to a variety of response biases; researchers recently called for supporting findings of self-reports with the assessment of interest in different ways, e.g. additional behavioral measures (Renninger \& Hidi, 2017). Future studies should consider alternative assessments of interest to further validate our findings.

\section{Conclusion}

How can we get students interested in learning materials? This has been one of the lingering questions among teachers and educators. Many technologies have been developed and implemented to make the learning materials look attractive and engaging, such as using animations and audios and including interactive components and fun activities. Such seductive details may be able to increase students' situational interest, but the effects are likely to be momentary and not sustainable, often even undermining their actual learning performance; (Harp \& Mayer, 1998; but see also Park et al., 
2011; Park et al., 2015). One important message from our research is that learning (i.e. knowledge acquisition) alone can have an impact on interest development and both should best be considered simultaneously.

\section{Acknowledgments}

We thank Jasmine Raw (University of Reading) for help with stimuli collection and proofreading. This research was supported in part by the Marie Curie Career Integration Grant, Award Number CIG630680 (Kou Murayama); Japan Society for the Promotion of Science Kakenhi, Grant Number 15H05401, 16H06406 and 18H01102 (Kou Murayama); F. J. McGuigan Early Career Investigator Prize from American Psychological Foundation (Kou Murayama); and Leverhulme Trust Research Project Grant, Award Number RPG-2016-146 and RL-2016-030 (Kou Murayama).

\section{Notes}

1. Whether we should distinguish the terms "curiosity" and "interest" is a matter of debate (Alexander, 2019), and the definitions of these terms are often different between studies (Grossnickle, 2016). We mainly use the term "interest" as we rely heavily on the literature of situational interest to inform our design and ideas. However, following the advice from Kidd and Hayden's (2015), we attempted to understand information search process from a broader perspective, and therefore cite and discuss the literature of curiosity when relevant, as long as these findings fit with the context of our research. For discussions on how situational interest and curiosity could be different, see Shin and Kim (2019).

\section{ORCID iD}

Greta M. Fastrich (D) https://orcid.org/0000-0001-7105-9091

\section{References}

Ainley, M., Hidi, S., \& Berndorff, D. (2002). Interest, learning, and the psychological processes that mediate their relationship. Journal of Educational Psychology, 94(3), 545-561. https://doi. org/10.1037/0022-0663.94.3.545

Alexander, P. A. (2019). Seeking common ground: Surveying the theoretical and empirical landscapes for curiosity and interest. Educational Psychology Review, 31(3), 897-904. https://doi. org/10.1007/s10648-019-09508-x

Alexander, P. A., Jetton, T. L., \& Kulikowich, J. M. (1995). Interrelationship of knowledge, interest, and recall: Assessing a model of domain learning. Journal of Educational Psychology, 87(4), 559-575. https://doi.org/10.1037/0022-0663.87.4.559

Alexander, P. A., Kulikowich, J. M., \& Schulze, S. K. (1994). How subject-matter knowledge affects recall and interest. American Educational Research Journal, 31(2), 313-337. https://doi. org/10.3102/00028312031002313

Anderson, R. C., Shirey, L. L., Wilson, Q. S., \& Fielding, L. G. (1987). Interestingness of children's reading material. In R. E. Snow, \& M. J. Farr (Eds.), Aptitude, learning and instruction (Vol. 3, pp. 287-299). Lawrence Erlbaum.

Berlyne, D. E. (1960). Conflict, arousal and curiosity. McGrawHill. https://doi.org/10.1037/11164-000
Biesanz, J. C., Deepb-Sossa, N., Papadakis, A. A., Bollen, K. A., \& Curran, P. J. (2004). The role of coding time in estimating and interpreting growth curve models. Psychological Methods, 9(1), 30-52. https://doi.org/10.1037/1082-989X.9.1.30

Cacioppo, J. T., \& Petty, R. E. (1982). The need for cognition. Journal of Personality and Social Psychology, 42(1), 116-131. https://doi.org/10.1037/0022-3514.42.1.116

Chen, A., Darst, P. W., \& Pangrazi, R. P. (2001). An examination of situational interest and its sources. British Journal of Educational Psychology, 71(3), 383-400. https://doi. org/10.1348/000709901158578

Durik, A. M., Shechter, O. G., Noh, M., Rozek, C. S., \& Harackiewicz, J. M. (2015). What if I can't? Success expectancies moderate the effects of utility value information on situational interest and performance. Motivation and Emotion, 39(1), 104-118. https://doi.org/10.1007/s11031-014-9419-0

Eccles, J., Wigfield, A., Harold, R. D., \& Blumenfeld, P. (1993). Age and gender differences in children's self- and task perceptions during elementary school. Child Development, 64(3), 830-847. https://doi.org/10.2307/1131221

Ennis, C. D., Cothran, C. J., Davidson, K. S., Loftus, S. J., Owens, L., Swanson, L., \& Hopsicker, P. (1997). Implementing curriculum within a context of fear and disengagement. Journal of Teaching in Physical Education, 17(1), 52-71. https://doi. org/10.1123/jtpe.17.1.52

Fulmer, S. M., \& Tulis, M. (2013). Changes in interest and affect during a difficult reading task: Relationships with perceived difficulty and reading fluency. Learning and Instruction, 27, 11-20. https://doi.org/10.1016/j.learninstruc.2013.02.001

GitHub. (n.d.). Gikeymarcia/Collector. https://github.com/gikeymarcia/Collector

Grossnickle, E. M. (2016). Disentangling curiosity: Dimensionality, definitions, and distinctions from interest in educational contexts. Educational Psychology Review, 28(1), 23-60. https:// doi.org/10.1007/s10648-014-9294-y

Harp, S. F., \& Mayer, R. E. (1998). How seductive details do their damage: A theory of cognitive interest in science learning. Journal of Educational Psychology, 90(3), 414-434. https://doi. org/10.1037/0022-0663.90.3.414

Hedelin, L., \& Sjöberg, L. (1989). The development of interests in the Swedish comprehensive school. European Journal of Psychology of Education, 4(1), Article 17. https://doi. org/10.1007/BF03172758

Hidi, S. (2016). Revisiting the role of rewards in motivation and learning: Implications of neuroscientific research. Educational Psychology Review, 28(1), 61-93. https://doi.org/10.1007/ s10648-015-9307-5

Hidi, S., \& Baird, W. (1986). Interestingness-A neglected variable in discourse processing. Cognitive Science, 10(2), 179194. https://doi.org/10.1207/s15516709 $\operatorname{cog} 1002 \_3$

Hidi, S., \& Renninger, K. A. (2006). The four-phase model of interest development. Educational Psychologist, 41(2), 111-127. https://doi.org/10.1207/s15326985ep4102_4

Holstermann, N., Ainley, M., Grube, D., Roick, T., \& Bögeholz, S. (2012). The specific relationship between disgust and interest: Relevance during biology class dissections and gender differences. Learning and Instruction, 22(3), 185-192. https://doi. org/10.1016/j.learninstruc.2011.10.005 
Kahn, B. E., \& Ratner, R. K. (2005). Variety for the sake of variety? In S. Ratneshwar, \& D. G. Mick (Eds.), Inside consumption: Consumer motives, goals, and desires (pp. 102-121). Routledge.

Kashdan, T. B., \& Steger, M. F. (2007). Curiosity and pathways to well-being and meaning in life: Traits, states, and everyday behaviors. Motivation and Emotion, 31(3), 159-173. https:// doi.org/10.1007/s11031-007-9068-7

Kidd, C., \& Hayden, B. Y. (2015). The psychology of neuroscience of curiosity. Neuron, 88(3), 449-460. https://doi.org/10.1016/j. neuron.2015.09.010

Kidd, C., Piantadosi, S. T., \& Aslin, R. N. (2012). The Goldilocks effect: Human infants allocate attention to visual sequences that are neither too simple nor too complex. PLoS ONE, 7(5), Article e36399. https://doi.org/10.1371/journal.pone.0036399

Kidd, C., Piantadosi, S. T., \& Aslin, R. N. (2014). The Goldilocks effect in infant auditory attention. Child development, 85(5), 1795-1804. https://doi.org/10.1111/cdev.12263

Kintsch, W. (1980). Learning from text, levels of comprehension, or: Why anyone would read a story anyway. Poetics, 9(1-3), 87-98. https://doi.org/10.1016/0304-422X(80)90013-3

Knogler, M., Harackiewicz, J. M., Gegenfurter, A., \& Lewalter, D. (2015). How situational is situational interest? Investigating the longitudinal structure of situational interest. Contemporary Educational Psychology, 43, 39-50. https://doi.org/10.1016/j. cedpsych.2015.08.004

Köller, O., Baumert, J., \& Schnabel, K. (2001). Does interest matter? The relationship between academic interest and achievement in mathematics. Journal for Research in Mathematics Education, 32(5), 448-470. https://doi.org/10.2307/749801

Krapp, A. (2002). An educational-psychological theory of interest and its relation to self-determination theory. In E. Deci, \& R. M. Ryan (Eds.), The handbook of self-determination research (pp. 405-427). University of Rochester Press.

Litman, J. A., Hutchins, T. L., \& Russon, R. K. (2005). Epistemic curiosity, feeling-of-knowing, and exploratory behaviour. Cognition and Emotion, 19(4), 559-582. https://doi. org/10.1080/02699930441000427

Litman, J. A., \& Jimerson, T. L. (2004). The measurement of curiosity as a feeling of deprivation. Journal of Personality Assessment, 82(2), 147-157. https://doi.org/10.1207/s15327752jpa8202_3

Loewenstein, G. (1994). The psychology of curiosity: A review and reinterpretation. Psychological Bulletin, 116(1), 75-98. https://doi.org/10.1037/0033-2909.116.1.75

Morton, A. (2010). Epistemic emotions. In P. Goldie (Ed.), The Oxford handbook of philosophy of emotion (pp. 385-399). Oxford University Press. https://doi.org/10.1093/oxfor dhb/9780199235018.003.0018

Murayama, K., Blake, A. B., Kerr, T., \& Castel, A. D. (2016). When enough is not enough: Information overload and metacognitive decisions to stop studying information. Journal of Experimental Psychology: Learning, Memory, and Cognition, 42(6), 914-924. https://doi.org/10.1037/xlm0000213

Murayama, K., FitzGibbon, L., \& Sakaki, M. (2019). Process account of curiosity and interest: A reward-learning perspective. Educational Psychology Review, 31(4), 875-895. https:// doi.org/10.1007/s10648-019-09499-9

Murayama, K., Goetz, T., Malmberg, L.-E., Pekrun, R., Tanaka, A., \& Martin, A. J. (2017). Within-person analysis in educational psychology: Importance and illustrations. In D. W. Putwain, \& K. Smart (Eds.), British Journal of Educational Psychology monograph series II: The role of competence beliefs in teaching and learning (pp. 71-87). Wiley.

Murayama, K., Izuma, K., Aoki, R., \& Matsumoto, K. (2016). "Your choice" motivates you in the brain: The emergence of autonomy neuroscience. In S. Kim, J. Reeve, \& M. Bong (Eds.), Recent developments in neuroscience research on human motivation (Vol. 19, pp. 95-125). Emerald. https://doi.org/10.1108/ S0749-742320160000019004

Muthén, B. O., \& Curran, P. J. (1997). General longitudinal modeling of individual differences in experimental designs: A latent variable framework for analysis and power estimation. Psychological Methods, 2(4), 371-402. https://doi. org/10.1037/1082-989X.2.4.371

Nye, C. D., Su, R., Rounds, J., \& Drasgow, F. (2012). Vocational interests and performance: A quantitative summary of over 60 years of research. Perspectives on Psychological Science, 7(4), 384-403. https://doi.org/10.1177/1745691612449021

Palmer, D. H. (2009). Student interest generated during an inquiry skills lesson. Journal of Research in Science Teaching, 46(2), 147-165. https://doi.org/10.1002/tea.20263

Park, B., Flowerday, T., \& Brünken, R. (2015). Cognitive and affective effects of seductive details in multimedia learning. Computers in Human Behavior, 44, 267-278. https://doi. org/10.1016/j.chb.2014.10.061

Park, B., Moreno, R., Seufert, T., \& Brünken, R. (2011). Does cognitive load moderate the seductive details effect? A multimedia study. Computers in Human Behavior, 27(1), 5-10. https://doi. org/10.1016/j.chb.2010.05.006

Patall, E. A., Cooper, H., \& Robinson, J. C. (2008). The effects of choice on intrinsic motivation and related outcomes: A metaanalysis of research findings. Psychological Bulletin, 134(2), 270-300. https://doi.org/10.1037/0033-2909.134.2.270

Patall, E. A., Vasquez, A. C., Steingut, R. R., Trimble, S. S., \& Pituch, K. A. (2016). Daily interest, engagement, and autonomy support in the high school science classroom. Contemporary Educational Psychology, 46, 180-194. https://doi.org/10.1016/j. cedpsych.2016.06.002

Pekrun, R., \& Linnenbrink-Garcia, L. (2014). Introduction to emotions in education. In R. Pekrun, \& L. Linnenbrink-Garcia (Eds.), International handbook of emotions in education (pp. 11-20). Routledge.

Pekrun, R., \& Stephens, E. J. (2012). Academic emotions. In K. R. Harris, S. Graham, T. Urdan, S. Graham, J. M. Royer, \& M. Zeidner (Eds.), APA handbooks in psychology. APA educational psychology handbook, Vol. 2: Individual differences and cultural and contextual factors (pp. 3-31). American Psychological Association. https://doi.org/10.1037/13274-001

Pressick-Kilborn, K. J. (2015). Canalization and connectedness in the development of science interest. In A. Renninger, M. Nieswandt, \& S. Hidi (Eds.), Interest in mathematics and science learning. American Psychological Association. https://doi. org/10.3102/978-0-935302-42-4_20

Randler, C., \& Bogner, F. X. (2007). Pupils' interest before, during, and after a curriculum dealing with ecological topics and its relationship with achievement. Educational Research and Evaluation, 13(5), 463-478. https://doi.org/10 $.1080 / 13803610701728295$ 
Ratner, R. K., Kahn, B. E., \& Kahnemann, D. (1999). Choosing lesspreferred experiences for the sake of variety. Journal of Consumer Research, 26(1), 1-15. https://doi.org/10.1086/209547

Raudenbush, S. W., Bryk, A. S., Cheong, Y. F., Congdon, R. T., \& du Toit, M. (2011). HLM 7: Hierarchical linear and nonlinear modelling. Scientific Software International.

Read, D., \& Loewenstein, G. (1995). Diversification bias: Explaining the discrepancy in variety seeking between combined and separated choices. Journal of Experimental Psychology: Applied, 1(1), 34-49. https://doi.org/10.1037/1076-898X.1.1.34

Renninger, K. A., \& Bachrach, J. E. (2015). Studying triggers for interest and engagement using observational methods. Educational Psychologist, 50(1), 58-69. https://doi.org/10.108 0/00461520.2014.999920

Renninger, K. A., \& Hidi, S. (2011). Revisiting the conceptualization, measurement, and generation of interest. Educational Psychologist, 46(3), 168-184. https://doi.org/10.1080/0046152 0.2011 .587723

Renninger, K. A., \& Hidi, S. (2017). The power of interest for motivation and learning. Routledge. https://doi. org/10.4324/9781315771045

Renninger, K. A., \& Su, S. (2012). Interest and its development. In R. Ryan (Ed.), The Oxford handbook of human motivation (pp. 167-187). Oxford University Press. https://doi.org/10.1093/oxf ordhb/9780195399820.013.0011

Richman, L. S., Kubzansky, L., Maselko, J., Kawachi, I., Choo, P., $\&$ Bauer, M. (2005). Positive emotion and health: Going beyond the negative. Health Psychology, 24(4), 422-429. https://doi. org/10.1037/0278-6133.24.4.422

Rotgans, J. I., \& Schmidt, H. G. (2011). Situational interest and academic achievement in the active-learning classroom. Learning and Instruction, 21(1), 58-67. https://doi.org/10.1016/j.learninstruc.2009.11.001

Ryan, R. M., \& Deci, E. L. (2000). Self-determination theory and the facilitation of intrinsic motivation, social development, and well-being. American Psychologist, 55(1), 68-78. https://doi. org/10.1037/0003-066X.55.1.68

Sadoski, M. (2001). Resolving the effects of concreteness on interest, comprehension, and learning important ideas from text. Educational Psychology Review, 13(3), 263-281. https://doi. org/10.1023/A:1016675822931

Sansone, C., Smith, J. L., Thoman, D. B., \& MacNamara, A. (2012). Regulating interest when learning online: Potential motivation and performance trade-offs. Internet and Higher Education, 15(3), 141-149. https://doi.org/10.1016/j.iheduc.2011.10.004
Schiefele, U. (2009). Situational and individual interest. In K. R. Wenzel, \& A. Wigfield (Eds.), Handbook of motivation at school (pp. 197-222). Routledge.

Schiefele, U., Krapp, A., \& Winteler, A. (1992). Interest as a predictor of academic achievement: A meta-analysis of research. In K. A. Renninger, S. Hidi, \& A. Krapp (Eds.), The role of interest in learning and development (pp. 183-212). Lawrence Erlbaum.

Schraw, G., Bruning, R., \& Svoboda, C. (1995). Sources of situational interest. Journal of Reading Behavior, 27(1), 1-17. https://doi.org/10.1080/10862969509547866

Shin, D. D., \& Kim, S. I. (2019). Homo curious: Curious or interested? Educational Psychology Review, 31(4), 853-874. https:// doi.org/10.1007/s10648-019-09497-x

Silvia, P. J. (2005). What is interesting? Exploring the appraisal structure of interest. Emotion, 5(1), 89-102. https://doi. org/10.1037/1528-3542.5.1.89

Swarat, S., Ortony, A., \& Revelle, W. (2012). Activity matters: Understanding student interest in school science. Journal of Research in Science Teaching, 49(4), 515-637. https://doi. org/10.1002/tea.21010

Tanaka, A., \& Murayama, K. (2014). Within-person analyses of situational interest and boredom: Interactions between task-specific perceptions and achievement goals. Journal of Educational Psychology, 106(4), 1122-1134. https://doi. org/10.1037/a0036659

Tapola, A., Veermans, M., \& Niemivirta, M. (2013). Predictors and outcomes of situational interest during a science learning task. Instructional Science, 41(6), 1047-1064. https://doi. org/10.1007/s11251-013-9273-6

Thoman, D. B., Sansone, C., \& Pasupathi, M. (2007). Talking about interest: Exploring the role of social interaction for regulating motivation and the interest experience. Journal of Happiness Studies, 8(3), 335-370. https://doi.org/10.1007/s10902-0069016-3

\section{Authors}

GRETA M. FASTRICH is a research associate at the University of Western Australia. Her research interests are decision making and motivation.

KOU MURAYAMA is a professor at the School of Psychology and Clinical Language Sciences, University of Reading. His research interest is motivation, learning, and metacognition. 